\section{Introduction to the Workshop}

\author{
Mark P. Bridgen ${ }^{1}$
}

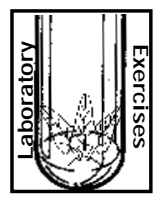

nstructors of plant tissue culture classes always are looking for new laboratory exercises. However, developing new exercises with plants other than Nicotianaand Daucus can be unsuccessful and time-consuming. In addition, instructors have to take into consideration the expectations of students, teaching assistants, and administrators. Instructors want laboratories that are reliable, can be completed within one semester, meet objectives valuable to the course, familiarize students with specific skills, have sufficient background information, and do not have lengthy planning and preparation. Administrators, during these times of budget cuts, would like exercises to be inexpensive. Teaching assistants prefer laboratories that areimplemented easily and outlined in detail to decrease confusion and keep laboratory reports short. Finally, the students want laboratories that are valuable, easy to follow, and clearly and concisely described; it also would beniceto haveaplant or culture of their own to take home.

Six seasoned instructors and authorities of plant tissueculture participated in this 1993 ASHS workshop. A description of plant regeneration from an axillary shoot proliferation system of Ajuga reptans is presented by John Preece. This exercise is unique, easy to implement, and demonstrates the four stages of micropropagation, the effects of cytokinin concentrations, and the differences between adventitious and axillary shoots.

For thoseinstructors looking for avery unique

Department of Plant Science, U-67, 1367 Storrs Road, University of Connecticut, Storrs, CT 06269-4067.

${ }^{1}$ Associate Professor of Floriculture and Ornamental Horticulture. in vitro sexual micropropagation exercise, Kenneth Mudgereviews aprocedurefor theasymbiotic seed germination, subculture, and outplanting of orchids. The exercise can be used to instruct students about orchid reproductive biology and symbiosis, as well as the skills involved in orchid seed sterilization and culture. Although scheduling the plants to flower and set seed is rather lengthy for the instructor, the detailed schedule is presented for stock plant flower pollination, capsule harvest and sowing, and seedling subculture.

Michael Kaneprovides an exercisethat demonstrates both direct and indirect shoot organogenesis from internodes of Myriophyllum aquaticum. Myriophyllumis aplant that responds quickly in vitro and is easy to establish, grow, and storeon agar-solidified medium.

Mark Bridgen presents another laboratory exercise to demonstrate direct and indirect organogenesis, but, in this procedure, organogenesis arises from leaf explants of Torenia fournieri. The in vitro production of adventitious shoots from Torenia is easy to control, seeds are inexpensive and easy to obtain, and plants are easy to grow. The laboratory also all ows modifications to learn about where callus originates on the explant, if abaxial or adaxial surfaces affect organogenesis, and what effect thesize of the explant has on organogenesis.

For those instructors who are bored with carrot somatic embryogenesis, Dennis Gray supplies an exercise for somatic embryogenesis of Dactylis glomerata. The exercise leads students through aspects of culture initiation, maintenance, and plant regeneration. This project with orchard grass not only demonstrates an interesting plant tissue culture procedure, it also helps to relate to the students the practical and economical importance of cell culture.

Finally, for those instructors that want alittle more "biotechnology" in their classes, Robert Trigiano presents a versatile laboratory on the transformation and organogenesis of a popular floricultural species - Dendranthemagrandiflora. Not only does the laboratory illustrate organogenesis and transformation, but the protocol explains five variations that can be used to demonstrate other concepts.

\section{A Laboratory Exercise for Axillary Shoot Proliferation using Ajuga reptans}

\author{
John E Preece and \\ Carl A. Huetteman
}

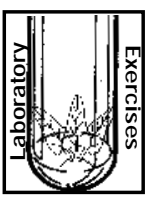

Additional index words. adventitious shoots, herbaceous perennial, in vitro, micropropagation, teaching, tissue culture

Summary. This exercise was developed for a plant propagation course to demonstrate, in a short time, the four stages of micropropagation, the effects of cytokinin concentrations, and the differences between adventitious and axillary shoots. Greenhouse-grown stock plants were brought into the laboratory, and 4- to 5-cm-long tips of runners were surface-dis-infested for 15 min in $0.5 \%$ NaCO with $1 \mathrm{ml}$ of Tween $20 /$ liter, followed by two 5-min rinses in sterile water. Working in the open laboratory near the bases of pairs of lit Bunsen burners, students placed either single-node or shoot tip explants ( $2 \mathrm{~cm}$ long, five replications) onto MS medium with 0,1 , or $10 \mu \mathrm{M} \mathrm{BA}$ Oultures were in-cubated in parafilm-sealed culture tubes on open laboratory benches. Axillary shoots grew regardless of concentration of BA, and explants on medium with $10 \mu \mathrm{M}$ BA produced the most callus and adventitious shoots. Microshoots were rooted and ac-climatized under mist in the greenhouse. This exercise can be performed in an open laboratory without the use of laminar flow hoods, specialized sterilizing equipment, or supplemental lighting.

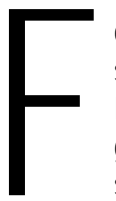

or several years, we were looking for a sufficiently rapid micropropagation laboratory exercise for a plant propagation course to demonstrate axillary shoot proliferation, rooting, and greenhouseacclimatization of plants. Based on timecon-

Department of Plant and Soil Science, Southern Illinois University, Carbondale, IL 62901.

We thank Midwest Groundcovers, Inc., St. Charles, III., for providing the Ajuga reptans plants. 
straints of asemester course, in vitro results must be obtained within 1 month, eliminating most species that we had tested. Therefore, laboratory exercises, such as the petunia(Fretzet al., 1979) or Salpiglossis (Lee et al., 1977) shoot organogenesis have been adopted for many plant propagation courses. Disadvantages of these exercises were that only adventitious shoot proliferation was demonstrated, and these species are propagated commercially by seeds and thus did not serve as appropriate models for commercial micropropagation.

We adapted the procedures published by Lineberger (1983) and Lineberger and Wanstreet (1983) for micropropagation of Ajugareptans to the plant propagation classroom. This exercise was developed to be conducted on open laboratory benches without special micropropagation teaching facilities, growth chambers, or light racks.

Thegeneral proceduresfor instructors to follow in preparing for this laboratory exercise are outlined in Table 1. We received stock plants of Ajuga reptans 'Braunherz' as a gift from Midwest Groundcovers, St. Charles, III. This cultivar is notachimera. Advantages and disadvantages of using chimeral Ajuga reptans stock plants are discussed later.

Stock plants mustbegrown in pots in agreenhouse to avoid microbial contamination. Weused a peat-litemedium similar to Promix BXand grew the plants under natural photoperiod at $24 \mathrm{C}$ (days) and 18C (nights). The plants were fertilized at each watering with a water-soluble fertilizer (200 ppm N from Peters Peat-Lite Special, 20N-4.4P-16.6K). Contamination rates were lower if plants were irrigated using a capillary mat (ebb and flood also would work well) compared to plants with overhead watering. Runner tips were harvested from stock plants during the March laboratory exercisefor usein the class. Young, vigorous stock plants well-spaced in the greenhouse with new, rapidly elongating runners have given us the best results. We have had up to $100 \%$ contamination when stock plants were too crowded in the greenhouse and/or were too old.

To demonstrate the effects of cytokinin on callus and shoot initiation and growth, and the differences between axillary and adventitious shoots, we have used three different media. Basal MS medium (Murashige and Skoog, 1962) with $30 \mathrm{~g}$ sucrose/liter, $7 \mathrm{~g}$ Sigma agar/liter, pH 5.8 (before agar and autoclaving) was supplemented with 0,1 , or $10 \mu \mathrm{M}$ benzyladenine (BA). These three media weretheonly treatmentstested in this exercise. Media weredispensed into $25 \times 150$-mm borosilicateglass culture tubes ( $15 \mathrm{ml} /$ tube) and capped with translucent autoclavable lids prior to autoclaving.

Becausestudents did all transfers in the open laboratory without benefit of transfer or laminar flow hoods, several special precautions and procedures were necessary to ensure asepsis. It was necessary in this exercise for the students to read and understand specific written directions prior to class. During the beginning of the laboratory period, the instructions were explained in detail, then the students reread the instructions again and committed

Table 1. Instructor's timetable for micropropagating Ajuga reptans on open laboratory benches.

Step Assignment

1. Bring healthy, young, greenhouse grown stock plants with rapidly elongating stems into the classroom laboratory prior to class.

2. Prepare and dispense media into culture tubes. Sterilize an adequate amount of water for rinses in an autoclave, or purchase sterilewater. Several small $(\leq 500 \mathrm{ml})$ vessels with al uminum foil over the tops work best for avoiding microbial contamination of the rinse water.

3. Stock the lab with adequate amounts of Bunsen burners (or al cohol lamps) and matches, liquid chlorine bleach, Tween 20 (or other wetting agent), disposablevinyl or rubber gloves, sterilepetri dishes (10 cm in diameter), 250$\mathrm{ml}$ beakers (or baby food jars or other suitable vessels), forceps, scal pels and blades, indelible marker pens, and paper towels or sponges.

4. Set up tissue culture stations.

A. Connect two Bunsen burners per station and place them 10 to $15 \mathrm{~cm}$ apart.

B. Placea250-ml beaker (or other suitablevessel) with onepair forcepsand onescal pel near theBunsen burners.

5. Explain the exercise and have students reread instructions and commit them to memory.

6. Have students remove all bags, books, clothing, etc., from the laboratory bench to an area of the room that will not be used.

7. Close all doors and windows.

8. Havestudents put on gloves and thoroughly soak and wash-down entire bench tops with 1 liquid chlorinebleach: 9 water $(\mathrm{v} / \mathrm{v})(0.5 \% \mathrm{NaClO}$ or $10 \%$ bleach) with paper towels or sponges.

9. Light Bunsen burners and completely fill beakers containing forceps with the $10 \%$ bleach solution.

10. Havestudents collect5-cm-long runner tips and removeall expanded leaves. Runner tipsaresurface-disinfested for 15 min in $0.5 \% \mathrm{NaClO}$ solution with $0.1 \%$ Tween 20 and then transferred to sterile rinse water in sterile petri dishes working near the bases of the two Bunsen burners. Have the students repeat the sterile water rinse.

11. Following surface disinfestation and rinsing, students should taketurns cutting explants and placing in vitro onto the various media working near the bases of the Bunsen burners.

12. Following transfers, culture tubes are labeled and placed in alight rack, growth chamber, or on the laboratory bench for incubation.

13. Before students leave, all laboratory benches are rinsed with tap water to remove bleach residue.

14. Data are collected weekly on shoot type, number, and length, callus growth, and microbial contamination.

15. When shoots are sufficiently long (after $\approx 1$ month), Ajugatissues are removed from the culture vessels using nonsterile technique.

16. Shoots are excised, planted into an appropriate rooting medium, and placed under intermittent mist.

17. Rooting data are collected as rooted shoots are transplanted. One week after transplanting, plants are placed on a greenhouse bench without mist.

them to memory. Sheets of paper were possible sources of microbial contamination and could not be present on the laboratory bench.

Students were instructed that, because this exercise does not use clean air hoods, it was only "representative" of commercial micropropagation, demonstrating many of the techniques. Additionally, it was emphasized that most of the practices during this laboratory period had one objective: to obtain and maintain asepsis.

After clearing and then washing bench tops with liberal amounts of bleach solution, and filling beakers containing scal pels and forceps with bleach solution, as described in Table 1, Bunsen burners (or alcohol lamps) were lit. The purpose of the burners was to create eddies of air moving upward. Airborne fungal spores or bacteria were caught in the updrafts and drawn away from the area around the base of the burner. It was only in this area that sterile containers were opened.

It was our experience that students were most successful working in pairs. More than two hands were necessary to do transfers in the open lab with lit Bunsen burners. One partner partially opened the petri dishes or the culture tubes, and the other shifted the plant tissues or poured sterile rinse water. Students were instructed to roll up their shirt sleeves and wash their hands and arms prior to putting on vinyl (or rubber) gloves and handling plant materials, containers, or bleach solutions.

Students excised fiveto ten 5 -cm-long runner tips, removed their leaves, and placed them in a plastic petri dish(Table1). Therunner tips weresurface-disinfested for $15 \mathrm{~min}$ in the covered plastic petri dish containing a solution of $0.5 \% \mathrm{NaClO}$ with $0.1 \%$ Tween 20 . Therunner tips were swirled gently a few times during this time period (students were instructed to be careful, because all of the bleach solution can be swirled out if they were overly vigorous). Working close to the base of the Bunsen burners, the runner tips were transferred carefully from thebleach solution to another sterilepetri dish containing sterile water. Swirling occasionally, the runner tips were rinsed in the water for $\approx 5 \mathrm{~min}$. This step was repeated after transferring to another petri dish containing sterile water.

In the third petri dish, after the second 5-min rinse, the shoots were cut into explants while in the rinse water to prevent desiccation. The original cut bases of the runner tips (lowest $5 \mathrm{~mm}$ ) were excised and discarded. The shoots were cut into 1.5- to 2.5$\mathrm{cm}$ nodal segments, each with one or two nodes, 
and all explants of equal length. Alternatively, 2-cmlong shoot tips were used by one group. To ensure that each student gained equal experience, one student cut half of the explants, then switched with their partner and held the petri dish open while the other student cut explants.

Working as partners, at thebase of the Bunsen burners, one partner opened culturetubes whilethe other placed explants vertically into the medium so that the lowest node was even with the surface of the medium. Tubes were recapped immediately after a transfer was made. Five replications of each me dium (total of 15 explants) were considered to be sufficient for this exercise.

Gloves were kept wet with the 10\% bleach solution (not containing wetting agent) throughout the laboratory period. However, students were instructed not to touch plant material with their hands/ gloves, other then when first collecting stem tips. Forceps and scalpels were dipped frequently into the bleach solution to decreaserisk of microbial contamination. Students and instructors walked very slowly and deliberately to avoid causing air currents that would carry spores into rinse waters or culturetubes.

Care was taken to avoid bleach making contact with clothing. Thebench tops weresoaked when washed, and leaning up against the benches has ruined clothing. Students were warned to wear old clothing for this laboratory exercise, but some students have forgotten, and large bleached spots appeared on their favorite pants and shirts. The fire from the Bunsen burners (or alcohol lamps) can ignite clothing, hair, or the building; therefore, appropriate care must be taken. Fire extinguishers should be available.

We had students place their cultures on a bench at the side of the laboratory with no special supplemental light. Thecool-whitefluorescentoverhead lamps were turned on only when there was a class in the laboratory room. North-facing windows provided some additional light, but the light level was quite variable from day to day and was not critical for growth of the explants. Becauseall of the cultures wereincubated under the same conditions, light was not a factor when comparing treatments.

Students should be instructed to collect data weekly (Table 2) to be used as the basis for the laboratory write-up. In addition to the data in Table 2 , students recorded information about microbial contamination. They were asked if contamination was fungal (fuzzy) or bacterial or yeast (smooth colony). They were instructed to observe if the contaminant was growing from the explant or along the sides of the vessel away from the explant. The types of contamination and their probable causes were discussed with the students. When the explants werefrom sufficiently young stock plants that were grown in agreenhouse, contamination did not exceed $20 \%$ using this protocol.

Shoots growing from leaf axils were re corded as axillary and those growing from callus (usually at the base of the explant inserted into the medium) were recorded as adventitious. Because cultures must remain aseptic, callus was easy to quantify using a rating scale $(0=$ none, $3=$ callus

Table 2. In vitro development of Ajuga reptans nodal segments in a 4-week classroom laboratory.

\begin{tabular}{|c|c|c|c|c|c|c|c|}
\hline \multirow[b]{2}{*}{ Week } & \multirow[b]{2}{*}{$\mathrm{BA}(\mu \mathrm{M})$} & \multicolumn{2}{|c|}{ Axillary shoots } & \multicolumn{2}{|c|}{ Adventitious shoots } & \multirow{2}{*}{$\begin{array}{c}\text { Callus rating } \\
(0-3)\end{array}$} & \multirow[b]{2}{*}{ No. roots } \\
\hline & & No. shoots & Length $(\mathrm{mm})$ & No. shoots & Length $(\mathrm{mm})$ & & \\
\hline \multirow[t]{4}{*}{1} & 0 & 0.9 & 28.1 & 0 & 0 & 0.0 & 0.93 \\
\hline & 1 & 0.9 & 28.5 & 0 & 0 & 0.14 & 2.07 \\
\hline & 10 & 1.0 & 13.0 & 0 & 0 & 0.20 & 1.67 \\
\hline & & NS & NS & & & NS & NS \\
\hline \multirow[t]{4}{*}{2} & 0 & 1.2 & 43.6 & 0 & 0 & 0.2 & 3.1 \\
\hline & 1 & 1.7 & 35.2 & 0 & 0 & 0.5 & 3.4 \\
\hline & 10 & 1.6 & 51.4 & 1.9 & 0.5 & 1.9 & 1.5 \\
\hline & & NS & NS & ** &.- & ** & NS \\
\hline \multirow[t]{4}{*}{3} & 0 & 1.3 & 71.4 & 0.2 & 1.3 & 0.3 & 3.9 \\
\hline & 1 & 2.2 & 64.8 & 0.3 & 1.1 & 0.6 & 4.6 \\
\hline & 10 & 1.7 & 63.2 & 4.7 & 4.7 & 3.0 & 1.6 \\
\hline & & NS & NS & ** & * & $* *$ & * \\
\hline \multirow[t]{4}{*}{4} & 0 & 1.4 & 110.9 & 0.3 & 2.3 & 0.3 & 4.8 \\
\hline & 1 & 2.9 & 119.4 & 0.6 & 22.4 & 0.9 & 6.9 \\
\hline & 10 & 2.1 & 152.9 & 5.6 & 59.5 & 3.0 & 2.3 \\
\hline & & NS & NS & ** & NS & $\star *$ & * \\
\hline
\end{tabular}

",NSSignificant at the 5\% level, $1 \%$ level, or nonsignificant, respectively, according to F test.

the diameter of the culture tube). Explants also rooted readily, and rooting responsewas recorded.

Axillary shoot number and length increased over the course of the experiment and cytokinin was notnecessary for growth of axillary shoots (Table2). However, there was a strong effect of cytokinin on adventitious shoot formation. Few formed in the absence of cytokinin in the medium, and the most formed when $10 \mu \mathrm{M}$ BA was included in the medium. Thesignificance of this regarding somaclonal variation was discussed with the students. Cytokinin likewisestimulated callus growth, and $10 \mu \mathrm{M}$ BA was inhibitory to rooting. The role of cytokinin in shoot and root initiation and growth also was discussed.

Following final data collection after 4 weeks, shoots were excised and rooted in a peat-lite medium under intermittent mist in the greenhouse. Axillary shoots were separated from adventitious shoots and shoots from explants cultured on the different levels of cytokinin were segregated. This was to allow the students to observe the differences among thesetreatment groups for rooting and acclimatization responses and to lookfor any somaclonal variability among the plants.

Virtually all shoots rooted within 2 weeks. The only shoots that did not root were afew of those that were $<5 \mathrm{~mm}$ long. Following rooting, containers were moved to areas of the mist bench receiving limited mist for 1 week. Plantlets then were transplanted and removed from mist.

Our plantlets showed no apparent somaclonal variation, possibly because the cultivar used was not chimeral. Using chimeral Ajuga cultivars, Lineberger (1983), Lineberger and Wanstreet (1983), and Zilis et al. (1979) reported that axillary shoots were true-to-type, and adventitious shoots were visibly variable. For the cultivar Burgundy Glow, a "bronze" somaclonal variant was most common (Lineberger, 1983; Lineberger and Wanstreet, 1983; Zilis et al., 1979). The cultivar Variegata produced solid green plants when regenerated adventitiously (Zlis et al., 1979). It was suggested that one of the chimeral types could be ideal for this laboratory exercise to demonstrate somaclonal variation with adventitious regeneration, compared to true-to-type plants with axillary shoot proliferation (R.D. Lineberger, personal communication).

Laboratory reportsfrom thestudentsincluded a statement of purpose, a description of materials and protocols, results in tabular or graph form, and adiscussion of theresults. Thegradewas based primarily on the discussion of reasons why the specific results were obtained. Follow-up topics and exam questions focused on differences between adventitious and axillary shoots, the micropropagation process, and the roles of micropropagation and biotechnology in the horticulture industry.

\section{Literature Cited}

Fretz, T.A., P.E. Read, and M.C. Peele. 1979. Plant propagation lab manual. 3rd ed. Burgess, Minneapolis.

Lee, C.W., R.M. Skirvin, A.I. Soltero, and J. Janick. 1977. Tissue culture of Salpiglossis sinuataL. from leaf discs. HortScience 12:547-549.

Lineberger, D. 1983. Micropropagation for the perennial industry, p. 7-17. In: E.M. Smith (ed.). Proc. Herbaceous Perennial Symp. Cooperative Extension Service, The Ohio State Univ. Bul. 717.

Lineberger, R.D. and A. Wanstreet. 1983. Micropropagation of Ajuga reptans 'Burgundy Glow'. Ornamental plants- 1983: A summary of research. The Ohio State Univ., Wooster. Res. Circ. 274:19-22.

Murashige, T. and F. Skoog. 1962. Arevised medium for rapid growth and bioassays with tobacco tissuecultures. Physiol. Plant. 15:473-497.

Zilis, M., D. Zwagerman, D. Lamberts, and L. Kurtz. 1979. Commercial propagation of herbaceous perennials by tissue culture. Comb. Proc. Intl. Plant Prop. Soc. 29:404413 